\title{
INFLUÊNCIA DE COLHEITAS PARCELADAS SOBRE A QUALIDADE DAS SEMENTES DE GERGELIM (SESAMUM INDICUM L.)
}

\section{Vicente de Paula Queiroga ${ }^{1}$, Rosa Maria Mendes Freire ${ }^{2}$, Paulo de Tarso Firmino ${ }^{2}$, Daise Ribeiro de Farias Marinho ${ }^{4}$, Enio Giuliano Girão ${ }^{2}$}

\author{
${ }^{1}$ Ph.D, Embrapa Algodão, vicente.queiroga@embrapa.br, Rua Osvaldo Cruz, 1143, Centenário, CEP 58428-095, Campina \\ Grande, PB, (83) 31824300, \\ ${ }^{2}$ M.Sc, Embrapa Algodão, rosa.freire@embrapa.br, paulo.firmino@embrapa.br, enio.girão@eembrapa.br \\ ${ }^{3}$ M.Sc, Embrapa Algodão, 4Analista B, Embrapa Algodão, daise.marinho@embrapa.br
}

RESUMO: Este trabalho teve como objetivo avaliar a influência das duas colheitas parceladas sobre a qualidade de sementes do gergelim: a) batedura aos 15 dias e b) batedura aos 25 dias. Utilizou-se o delineamento inteiramente casualizado com oito repetições. Os testes de laboratório estudados foram: germinação, vigor (primeira contagem de germinação, comprimento de plântula e condutividade elétrica), pureza física, teor de água, teor de óleo, proteína, cinza, fósforo $(\mathrm{P})$, potássio $(\mathrm{K})$, cálcio $(\mathrm{Ca})$ e enxofre $(\mathrm{S})$. As conclusões estabelecidas foram: 1) Dependendo da colheita do gergelim, quando realizada em total ausência de chuvas, os componentes fisiológicos (condutividade elétrica e pureza física), químicos (teores de água, óleo e cinza) e o mineral $\mathrm{K}$ das sementes sofreram alterações significativas, mesmo diante da influência das sementes provenientes de diferentes épocas de batedura dos feixes; e 2) Em geral, há uma tendência para as sementes da segunda batedura ( 25 dias) apresentar qualidade inferior ao tratamento primeira batedura.

PALAVRAS-CHAVE: Sesamum indicum, colheita, qualidade fisiológica, composição química e mineral

\section{THE INFLUENCE OF CROPS IN INSTALLMENTS ON THE QUALITY OF SESAME SEEDS (SESAMUM INDICUM L.)}

\begin{abstract}
This work aimed to evaluate the influence of both in installment crops on the quality of the sesame seeds: a) batting at 15 days and b) batting at 25 days. We used a completely randomized design with eight replications. Laboratory tests were: germination, vigor (first count of germination, seedling length and electrical conductivity), physical purity, moisture content, oil content, protein, ash, phosphorus $(\mathrm{P})$, potassium $(\mathrm{K})$, calcium $(\mathrm{Ca})$ and sulfur (S). The conclusions were established: 1) Depending on the harvest of sesame, when performed in a total absence of rain, the physiological components (conductivity and physical purity), chemicals (moisture content, oil content and ash) and the mineral $\mathrm{K}$ of the seeds have undergone significant changes, despite the influence of seed from different seasons of batting beams; and 2) in general, there is a tendency for the seeds of batting second ( 25 days) to show a lower quality than the ones of the first batting treatment.
\end{abstract}

KEYWORDS: Sesamum indicum, harvest, physiological quality, chemical and mineral composition. 


\section{INTRODUÇÃO}

Dentre as operações desenvolvidas com esta cultura, a colheita é uma operação de grande relevância no momento exato da colheita quando os frutos da base das hastes começam a abrirse, produzem sementes em maior número e de maior tamanho, pois daí em diante a deiscência dos frutos progride rapidamente, chegando àqueles localizados no topo da planta (QUEIROGA et al., 2010).

De modo geral, a batedura dos feixes ocorre aos 8, 15 e 22 dias após o corte das plantas de gergelim nas diferentes comunidades do Piauí. A terceira batedura destina-se a coleta das sementes do ápice das plantas. Devido a sua baixa qualidade (sementes imaturas e palhas), recomenda-se separá-las das demais sementes, obtidas da primeira e da segunda batedura. Caso se necessite complementar a secagem das sementes após a batedura, é recomendável espalhar uma camada fina de sementes sobre a lona plástica, em razão de que as mesmas terão que apresentar umidade máxima de 4,5\% para o acondicionamento em embalagem hermética (QUEIROGA et al., 2008; 2010). O presente trabalho teve como objetivo avaliar as colheitas parceladas (bateduras), com a finalidade de estudar suas influências sobre a qualidade das sementes.

\section{MATERIAL E MÉTODOS}

As pesquisas foram conduzidas nos Laboratórios de Análise de Sementes e de Química de Campina Grande-PB e na Estação Experimental de Patos, PB (colheita e beneficiamento). Foram utilizadas sementes da cultivar BRS Seda, safra agrícola de 2011.

As sementes de gergelim (Sesamum indicum L.) foram provenientes do campo de $1 / 2$ hectare de produção de sementes cultivar BRS Seda, na Estação Experimental da Embrapa Algodão, Patos, PB, o qual foi plantado no início de março de 2011 em regime de sequeiro no espaçamento de $90 \mathrm{~cm}$ entre fileiras, deixando 12 plantas por metro linear.

Este trabalho envolveu as sementes provenientes de duas épocas de batedura dos feixes em relação ao corte da planta: a) batedura aos 15 dias e b) batedura aos 25 dias. Em seguida, os feixes de gergelim de cada tratamento foram submetidos separadamente ao processo de secagem ao sol. Uma vez completada a secagem dos frutos, as sementes de cada tratamento foram submetidas aos distintos processos de peneiração e ventilação. Essa quantidade de sementes por cada tratamento foi de $1 \mathrm{~kg}$.

Para cada época de batedura, foram realizados os seguintes testes de laboratório: germinação, testes de vigor (primeira contagem de germinação, comprimento de plântula e condutividade elétrica), análise de pureza, teor de água, teor de óleo, teor de proteína, cinza e composição mineral (P, K, Ca e S). Estes testes foram efetuados nos Laboratórios de Sementes e de Química da Embrapa Algodão de Campina Grande-PB. 


\section{RESULTADOS E DISCUSSÃO}

\section{Qualidade fisiológica}

As análises de variância correspondentes às características de germinação, vigor ( $1^{\text {a }}$ contagem de germinação, comprimento de plântula e condutividade elétrica) e análise de pureza em função de duas épocas de batedura dos feixes após o corte da planta, encontram-se na Tabela 1. Observa-se que existem diferenças significativas apenas para as variáveis condutividade elétrica e análise de pureza nos níveis de significância de $1 \%$ e 5\%, respectivamente.

Com relação à Tabela 2, verificam-se valores significativamente diferentes do vigor, através do teste de condutividade elétrica, e análise de pureza, tendo as sementes provenientes da segunda batedura dos feixes aos 25 dias após o corte da planta de gergelim apresentado menor qualidade em comparação as sementes obtidas na primeira batedura. Segundo AbdulBaki e Anderson (1970) afirmam que a maior liberação de exsudatos da semente está associada com a deterioração das sementes.

Tabela 1. Análise de variância (quadrados médios) e coeficiente de variação (cv) correspondente à qualidade fisiológica de sementes de gergelim em função de duas épocas de batedura dos feixes após o corte da planta. Campina Grande, PB, 2011

\begin{tabular}{lcccccc}
\hline & & \multicolumn{5}{c}{ QUADRADOS MÉDIOS } \\
\cline { 3 - 7 } Fonte de & GL & Germinação & $\begin{array}{c}1^{\mathrm{a}} \\
\text { Contagem } \\
\text { Germinação }\end{array}$ & $\begin{array}{c}\text { Comprimento } \\
\text { de Plântula }\end{array}$ & Condutividade & Pureza \\
\hline Bateduras & 1 & $8,85^{\mathrm{ns}}$ & $8,85^{\mathrm{ns}}$ & $1,75^{\mathrm{ns}}$ & $1042951,56^{* *}$ & $6480,50^{*}$ \\
Resíduo & 14 & 0,96 & 0,96 & 0,20 & 98,56 & 20,85 \\
CV $(\%)$ & & 1,01 & 1,01 & 11,38 & 1,32 & 5,81 \\
\hline
\end{tabular}

${ }^{\mathrm{ns}}$ não significativo; ${ }^{*}$ significativo $(\mathrm{p}<0,05) ;{ }^{* *}$ significativo $(\mathrm{p}<0,01)$

Tabela 2. Valores médios correspondentes a qualidade fisiológica sementes de gergelim em função de duas épocas de batedura dos feixes após o corte da planta. Campina Grande, PB, 2011

\begin{tabular}{|c|c|c|c|c|c|}
\hline \multirow[b]{2}{*}{$\begin{array}{c}\text { Épocas de } \\
\text { batedura dos } \\
\text { feixes após o } \\
\text { corte da planta }\end{array}$} & \multicolumn{5}{|c|}{ VARIÁVEIS } \\
\hline & $\begin{array}{c}\text { Germinação } \\
(\%)\end{array}$ & $\begin{array}{c}1^{\mathrm{a}} \\
\text { Contagem } \\
\text { Germinação } \\
(\%)\end{array}$ & $\begin{array}{l}\text { Comprimento } \\
\text { de Plântula } \\
\text { (cm) }\end{array}$ & $\begin{array}{l}\text { Condutividade } \\
\text { Elétrica } \\
\left(\mu \mathrm{S} . \mathrm{cm}^{-1} \cdot \mathrm{g}^{-1}\right)\end{array}$ & $\begin{array}{l}\text { Análise de } \\
\text { Pureza } \\
(\%)\end{array}$ \\
\hline $\begin{array}{ll}\text { Bateduras } & 15 \\
\text { dias }\end{array}$ & $98,0 \mathrm{a}$ & $98,05 \mathrm{a}$ & $4,3 \mathrm{a}$ & $496,02 \mathrm{~b}$ & 86,5 a \\
\hline $\begin{array}{l}\text { Bateduras } 25 \\
\text { dias }\end{array}$ & $96,5 \mathrm{a}$ & $96,5 \mathrm{a}$ & $3,9 \mathrm{a}$ & $1006,6 \mathrm{a}$ & $70,7 \mathrm{~b}$ \\
\hline DMS & 1,64 & 1,64 & 0,5 & 10,63 & 7,8 \\
\hline
\end{tabular}


As análises de variância correspondentes às características: teor de água, óleo, proteína e cinzas, obtidas de sementes de gergelim em função de duas épocas de batedura dos feixes após o corte da planta, estão representadas na Tabela 3. Verifica-se que houve diferenças significativas nos componentes químicos teor de água, óleo e cinzas das sementes, enquanto para a variável proteína não houve significância estatística.

Tabela 3. Análise de variância (quadrados médios) e coeficiente de variação (cv) correspondente à composição química de sementes de gergelim em função de duas épocas de batedura dos feixes após o corte da planta. Campina Grande, PB, 2011

\begin{tabular}{lccccc}
\hline \multirow{2}{*}{$\begin{array}{l}\text { Fonte de } \\
\text { Variação }\end{array}$} & \multirow{2}{*}{ GL } & \multicolumn{4}{c}{ QUADRADOS MÉDIOS } \\
\cline { 3 - 6 } & & Teor de Água & Óleo & Proteína & Cinza \\
\hline Bateduras & 1 & $0,27^{* *}$ & $42,575^{* *}$ & $0,823^{\mathrm{ns}}$ & $0,701^{* *}$ \\
Resíduo & 14 & 0,001 & 0,546 & 0,353 & 0,002 \\
$\mathrm{CV}(\%)$ & & 0,67 & 1,45 & 2,87 & 1,19 \\
\hline
\end{tabular}

${ }^{\mathrm{ns}}$ não significativo; $*$ significativo $(\mathrm{p}<0,05) ; * *$ significativo $(\mathrm{p}<0,01)$

Analisando-se os resultados dos componentes químicos (teor de água, óleo, proteína e cinza) provenientes das sementes de duas bateduras (Tabela 4), constata-se nas variáveis teores de água e cinzas uma superioridade significativa das sementes colhidas aos 25 dias em relação às colhidas aos 15 dias. $\mathrm{O}$ contrário ocorreu para a variável percentagem de óleo, onde as sementes provenientes da batedura de 15 dias deferiram significativamente das sementes da batedura de 25 dias. Estes valores significativos do óleo das sementes colhidas aos 15 dias $(52,45 \%)$ eram esperados, em virtude de que as sementes da segunda batedura (25 dias) por apresentarem maior quantidade de sementes imaturas na parte apical da planta, consequentemente, essas sementes produzem menos óleo $(49,19 \%)$ pelo fato do processo de enchimento das mesmas não ter sido plenamente completado (QUEIROGA et al., 2010).

Tabela 4. Composição química das sementes de gergelim em função de duas épocas de batedura dos feixes após o corte da planta. Campina Grande, PB, 2011.

\begin{tabular}{lcccc}
\hline \multirow{2}{*}{$\begin{array}{c}\text { Épocas de batedura } \\
\text { dos feixes após o corte } \\
\text { da planta }\end{array}$} & Teor de Água & Óleo & Proteína & Cinza \\
\cline { 2 - 5 } & & & & \\
\hline Bateduras 15 dias & $5,62 \mathrm{~b}$ & $52,45 \mathrm{a}$ & $20,50 \mathrm{a}$ & $4,30 \mathrm{~b}$ \\
Bateduras 25 dias & $5,88 \mathrm{a}$ & $49,19 \mathrm{~b}$ & $20,95 \mathrm{a}$ & $4,72 \mathrm{a}$ \\
\hline DMS & 0,04 & 0,79 & 0,63 & 0,05 \\
\hline Médias seguidas pela mesma letra nas colunas não diferem estatisticamente, pelo teste de Tukey, a 5\% de \\
probabilidade.
\end{tabular}




\section{Composição mineral}

As análises de variância correspondentes à caracterização dos elementos minerais fósforo $(\mathrm{P})$, potássio $(\mathrm{K})$, cálcio $(\mathrm{Ca})$ e enxofre $(\mathrm{S})$, obtidos de sementes de gergelim em função de duas épocas de batedura dos feixes após o corte da planta, encontram-se na Tabela 5. Observa-se que apenas o potássio apresentou diferenças significativas ao nível de $1 \%$ de probabilidade.

Tabela 5. Análise de variância (quadrados médios) e coeficiente de variação (cv) correspondente à caracterização dos elementos minerais de gergelim em função de duas épocas de batedura dos feixes após o corte da planta. Campina Grande, PB, 2011

\begin{tabular}{lccccc}
\hline \multirow{2}{*}{$\begin{array}{l}\text { Fonte de } \\
\text { Variação }\end{array}$} & GL & \multicolumn{4}{c}{ QUADRADOS MÉDIOS } \\
\cline { 3 - 6 } & & $\mathrm{P}$ & $\mathrm{K}$ & $\mathrm{Ca}$ & $\mathrm{S}$ \\
\hline Bateduras & 1 & $23509,32^{\mathrm{ns}}$ & $30800,25^{* *}$ & $2304,00^{\mathrm{ns}}$ & $0,27^{\mathrm{ns}}$ \\
Resíduo & 14 & 7964,66 & 31,53 & 3645,64 & 69,17 \\
$\mathrm{CV}(\%)$ & & 21,50 & 1,76 & 6,32 & 3,30 \\
\hline
\end{tabular}

${ }^{\mathrm{ns}}$ não significativo; * significativo $(\mathrm{p}<0,05) ; * *$ significativo $(\mathrm{p}<0,01)$

$\mathrm{Na}$ Tabela 6, observa-se a superioridade significativa das sementes provenientes da batedura realizada aos 25 dias para o elemento mineral potássio $(\mathrm{K})$ em relação às sementes da batedura dos 15 dias, sendo que esse mesmo comportamento ocorreu nos demais elementos minerais ( $\mathrm{P}, \mathrm{Ca}$ e $\mathrm{S}$ ), com a exceção de que não houve diferenças significativas entre os tratamentos estudados (primeira e segunda batida).

Tabela 6. Caracterização dos elementos minerais em sementes de gergelim em função de duas épocas de batedura dos feixes após o corte da planta. Campina Grande, PB, 2011

\begin{tabular}{ccccc}
\hline Épocas de batedura & \multicolumn{4}{c}{ VARIÁVEIS (mg/100 g) } \\
\cline { 2 - 5 } dos feixes após o corte & $\mathrm{P}$ & $\mathrm{K}$ & $\mathrm{Ca}$ & $\mathrm{S}$ \\
\hline da planta & $376,67 \mathrm{a}$ & $274,75 \mathrm{~b}$ & $943,25 \mathrm{a}$ & $252,11 \mathrm{a}$ \\
Bateduras 15 dias & $453,33 \mathrm{a}$ & $362,50 \mathrm{a}$ & $967,25 \mathrm{a}$ & $252,37 \mathrm{a}$ \\
\hline Bateduras 25 dias & 95,60 & 6,01 & 64,68 & 8,90 \\
\hline DMS &
\end{tabular}

Médias seguidas pela mesma letra nas colunas não diferem estatisticamente, pelo teste de Tukey, a 5\% de probabilidade.

\section{CONCLUSÕES}

- Constatou-se tendência de destaque das sementes provenientes da primeira batedura (15 dias) com relação às variáveis: condutividade elétrica, análise de pureza e teor de óleo;

- As sementes da segunda batedura (25 dias) destacaram nas variáveis: teor de água, teor de cinzas e o elemento mineral potássio.

\section{REFERÊNCIAS}


ABDUL-BAKI, A.A.; ANDERSON, J.D. Viability and leaching of sugars from germ inating barley. Crop Science, Madison, v.10, n.1, p.31-34, 1970.

QUEIROGA, V.P.; GONDIM, T.M.S.; VALE, D.G.; GEREON, H.G.M.; MOURA, J.A.; SILVA, P.J.; SOUZA FILHO, J.F. Produção de gergelim orgânico nas comunidades de produtores familiares de São Francisco de Assis do Piauí. Campina Grande: Embrapa Algodão, 2008. 127p. (Embrapa Algodão. Documentos, 190).

QUEIROGA, V.P; SILVA, O.R.R.F. Tecnologias utilizadas no cultivo do gergelim mecanizado. Campina Grande: Embrapa Algodão, 2008.142p. (Embrapa Algodão. Documentos, 203).

QUEIROGA, V.P.; GONDIM, T.M.S FIRMINO, P.T.; SILVA, A.C; QUEIROGA, D.A.N. Colheita manual e diferentes formas de aproveitamento de grãos de gergelim. Revista Agro@mbiente On-line, v.4,n.2, p.110-117,jul-dez, 2010. 